\title{
PEMODELAN MATEMATIKA ALIRAN DARAH PADA PEMBULUH DARAH ARTERI DAN VENA PADA KELAINAN JANTUNG SINGLE VENTRICLE
}

\author{
Mutia Aris Pradina ${ }^{1}$, Arif Fatahillah ${ }^{2}$, Susi Setiawan ${ }^{2}$ \\ Program Studi (S1) Pendidikan Matematika, FKIP, Universitas Jember (UNEJ) \\ Jalan Kalimantan 37 Kampus Tegalboto Jember 68121 \\ E-mail: mutiaarispradina@gmail.com
}

\begin{abstract}
Single ventricle is a heart defect in which one of the ventricle does not developed and bother the blood flow. One of the solutions is fontan surgery. The result of Fontan surgery allows the blood flowing in veins that initially lead to the heart change into the arteries. Because of these changes, there are possibility of swelling and velocity change of blood flowing. This research constructed a mathematical model of blood flowing velocity in arteries and veins due to a single ventricle heart defect that was formed from the momentum and mass equation, which was influenced by the diameter of venous vessel and blood viscosity. The analysis of the blood flow velocity in arteries and veins due to single ventricle heart defect was simulated by MATLAB and FLUENT software. The factors observed were the effect of venous diameter and blood viscosity on the velocity of blood flow in the veins. The result indicated that the greater diameter of the vein, the smaller the flow velocity in the vein. The greater blood viscosity resulted the smaller flow velocity in arteries and veins.
\end{abstract}

Keywords: Finite Volume Method, Mathematical Model, Single Ventricle, Fontan

\section{PENDAHULUAN}

Matematika merupakan ilmu yang menjadi dasar dalam mengembangkan ilmuilmu lainnya [1]. Matematika sendiri memiliki banyak cabang ilmu, salah satunya adalah pemodelan matematika. Matematika sering kali membantu menyelesaikan permasalahan dalam kehidupan sehari-hari, yang khususnya berkaitan dengan komputasi. Permasalahan kehidupan sehari-hari tentunya sangat banyak, salah satunya adalah dalam hal kesehatan. Penduduk Indonesia semakin besar yang menyukai makanan siap saji atau yang sering disebut dengan fast food, tentu akan memberikan dampak yang kurang baik terhadap kesehatan. Kesehatan yang harus dijaga oleh manusia mencakup banyak hal, misalnya pada kesehatan jantung.

Penyakit jantung bawaan (PJB) merupakan kelainan kongenital yang paling umum dan sebagai jenis penyakit jantung terbanyak pada anak. Kelainan Jantung bawaan dikelompokkan atas 2 bagian yaitu PJB non sianotik dan PJB sianotik. Bagian dari PJB

\footnotetext{
${ }^{1}$ Mahasiswa S-1 Prodi Pendidikan Matematika FKIP Universitas Jember

${ }^{2}$ Dosen Prodi Pendidikan Matematika FKIP Universitas Jember
} 
non sianotik antara lain Ventricle septal defect (VSD), Atrial septal defect (ASD), dan Patent ductus arteriosus (PDA). Sedangkan pada PJB sianotik antara lain Tetralogy of Fallot (TOF), Transposition of great arteries (TGA), dan Single ventricle (SV) [2].

Single Ventricle (SV) adalah suatu kelainan kongenital dimana salah satu dari kedua ventrikel tidak berkembang (hypoplasia) atau tidak terbentuk (absent). Terapi bedah ditujukan untuk menyiapkan jantung dengan SV ini agar dapat mengalirkan darah yang mengandung oksigen ke sirkulasi sistemik, dan darah yang tidak teroksigenasi dialirkan ke sirkulasi pulmonal tanpa melewati ventrikel. Pasien dengan SV dapat bertahan hidup dalam waktu yang lebih lama seiring dengan adanya perbaikan dari segi teknik operasi maupun perawatan medis. Semua pasien dengan fisiologi SV yang mempunyai satu ventrikel yang tidak berkembang, pada akhirnya akan ditatalaksana dengan fisiologi Fontan. Sedangkan pasien dengan fisiologi SV dan memiliki dua ventrikel yang berkembang dengan baik, akan menjalani prosedur perbaikan seperti layaknya jantung normal dengan dua ventrikel [3].

Model matematika adalah representasi dari sistem nyata yang dijabarkan dalam bentuk simbol dan pernyataan matematika. Berdasarkan hal tersebut, model matematika merepresentasikan sebuah sistem dalam bentuk hubungan kuantitatif dan logika, berupa suatu persamaan matematika [4]. Pemodelan matematika merupakan usaha perancangan rumusan matematika yang secara potensional menggambarkan bagaimana mendapatkan penyelesaian masalah matematika yang digeneralisasikan untuk diterapkan pada perilaku atau kejadian alam. Jadi pemodelan matematika merupakan proses untuk mempresentasikan sistem atau masalah di dunia nyata ke dalam pernyataan matematika [5]. Pemodelan matematika diperlukan dalam berbagai bidang misalnya bidang kedokteran dan fisika, salah satunya yaitu mengetahui kecepatan aliran darah. Kecepatan aliran darah akibat kelainan jantung single ventricle dapat dikaji menggunakan beberapa faktor yang mempengaruhi kecepatan aliran darah.

Dalam penelitian Cheng, A. L. dkk yang berjudul "Experimental investigation of the effect of non-Newtonian behavior of blood flow in the Fontan circulation" mensimulasikan aliran peredaran darah yang terjadi akibat sirkulasi Fontan yang dipengaruhi oleh kandungan glycerol dan xanthan gum dalam darah. Hasil yang didapat ialah kecepatan aliran darah yang mengandung glycerol lebih tinggi dari pada kecepatan aliran darah yang mengandung xanthan gum [6]. 
Berdasarkan uraian di atas, maka tujuan dari penelitian ini membentuk dan mengembangkan model matematika kecepatan aliran darah pada pembuluh darah arteri dan vena akibat kelainan jantung single ventricle, menganalisis pengaruh diameter pembuluh vena dan viskositas yang berbeda. Model matematika diselesaikan menggunakan metode volume hingga dan didiskritisasi QUICK.

\section{METODE PENELITIAN}

Metode penelitian merupakan tahap yang dilakukan untuk mendapatkan data yang akan dianalisis untuk sampai pada kesimpulan yang konsisten dengan tujuan penelitian. Penelitian ini merupakan jenis penelitian simulasi. Jenis penelitian simulasi ini memiliki tujuan untuk meniru suatu yang nyata dalam kehidupan sehari-hari secara sistematis kemudian dipelajari sifat dan karakteristiknya. Pada penelitian ini memodelkan kecepatan aliran darah pada arteri pulmonalis dan vena kava akibat dari bedah fontan yang dilakukan pada kelainan jantung Single Ventricle. Langkah pertama yaitu melakukan studi pustaka tentang kelainan jantung single ventricle. Langkah selanjutnya membuat representasi dari sistem nyata dalam bentuk model matematika. Sehingga diperoleh hasil atau data-data yang mendekati keadaan yang sebenarnya.

\section{HASIL PENELITIAN}

Analisis numerik kecepatan aliran darah pada pembuluh darah arteri dan vena akibat kelainan jantung single ventricle dilakukan dengan beberapa tahap. Tahap pertama yaitu dengan pembentukan model matematika yang didasarkan pada persamaan massa dan persamaan momentum. Persamaan massa yang digunakan berdasarkan hukum kekekalan massa, Persamaan momentum merupakan bentuk persamaan diferensial yang menghubungkan gaya-gaya yang bekerja pada volume kendali yaitu gaya tekanan $(P)$ dan tegangan geser $(\tau)$. Berikut merupakan skema kendali persamaan massa aliran darah pada pembuluh darah arteri dan vena akibat kelainan jantung single ventricle.

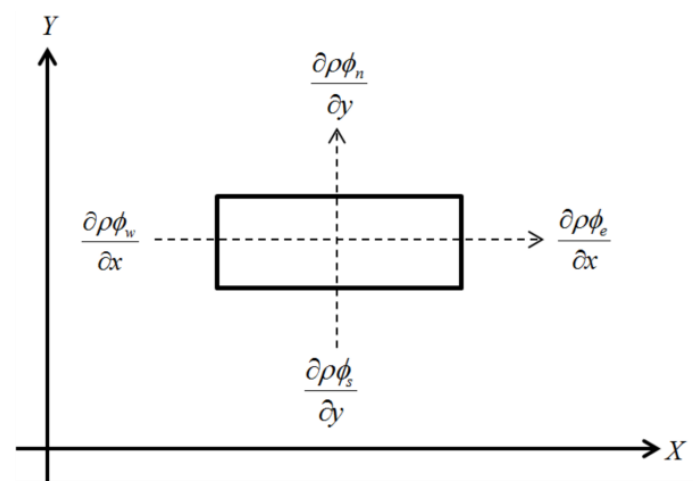


Gambar 1. Skema Kendali Persamaan Massa

Maka persamaan massa yang diperoleh sebagai berikut

$$
\begin{aligned}
& \frac{\partial \rho \phi_{0}}{\partial t}+[\text { pure rate }]=0 \\
& \frac{\partial \rho \phi_{0}}{\partial t}+[\text { input }- \text { output }]=0 \\
& \frac{\partial \rho \phi_{0}}{\partial t}+\frac{\partial \rho \phi_{w}}{\partial x}-\frac{\partial \rho \phi_{e}}{\partial x}+\frac{\partial \rho \phi_{s}}{\partial y}-\frac{\partial \rho \phi_{n}}{\partial y}=0
\end{aligned}
$$

Selain menggunakan persamaan massa, alirah darah pada pembuluh darah arteri dan vena akibat kelainan jantung single ventricle juga menggunakan persamaan momentum.

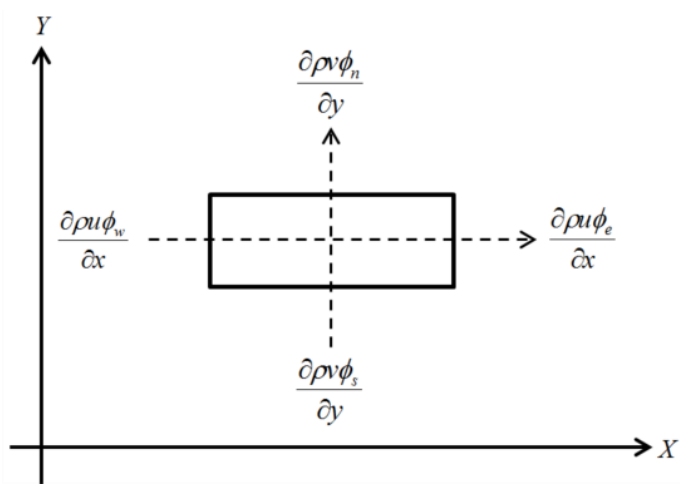

Gambar 2. Skema Kendali Persamaan Momentum

Dari skema kendali persamaan momentum di atas maka persamaan momentum yang diperoleh sebagai berikut:

$$
\begin{aligned}
& \frac{\partial \rho \phi_{0}}{\partial t}+[\text { pure rate }]=\sum F \\
& \frac{\partial \rho \phi_{0}}{\partial t}+[\text { input }- \text { output }]=\sum F \\
& \frac{\partial \rho \phi_{0}}{\partial t}+\frac{\partial \rho u \phi_{w}}{\partial x}-\frac{\partial \rho u \phi_{e}}{\partial x}+\frac{\partial \rho u \phi_{s}}{\partial y}-\frac{\partial \rho u \phi_{n}}{\partial y}= \\
& -\frac{\partial P}{\partial x}-\frac{\partial P}{\partial y}+2 \mu \frac{\partial^{2} u}{\partial x^{2}}+2 \mu \frac{\partial u}{\partial x}+2 \mu \frac{\partial^{2} v}{\partial y^{2}}+2 \mu \frac{\partial v}{\partial y}
\end{aligned}
$$

Penyelesaian model matematika menggunakan metode volume hingga dengan mengintegralkan persamaan massa dan persamaan momentum terhadap tiga variabel yaitu $x, y$ dan $t[1]$. Berikut merupakan bentuk integral dari persamaan massa.

$$
\begin{array}{r}
\int_{t}^{t+\Delta t} \int_{y}^{y+\Delta y} \int_{x}^{x+\Delta x}\left[\frac{\partial \rho \phi_{0}}{\partial t}+\frac{\partial \rho \phi_{w}}{\partial x}-\frac{\partial \rho \phi_{e}}{\partial x}+\frac{\partial \rho \phi_{s}}{\partial y}-\frac{\partial \rho \phi_{n}}{\partial y}\right] d x d y d t= \\
\int_{t}^{t+\Delta t} \int_{y}^{y+\Delta y} \int_{x}^{x+\Delta x} 0 d x d y d t
\end{array}
$$


Maka diperoleh model akhir persamaan massa aliran darah pada pembuluh darah arteri dan vena akibat kelainan jantung single ventricle sebagai berikut:

$$
\begin{aligned}
& \rho \phi_{0} \Delta y \Delta x+\rho \phi_{w} \Delta t \Delta y-\rho \phi_{e} \Delta t \Delta y+\rho \phi_{s} \Delta t \Delta x-\rho \phi_{n} \Delta t \Delta x=0 \\
& \phi_{0}=-\phi_{w} \frac{\Delta t}{\Delta x}+\phi_{e} \frac{\Delta t}{\Delta x}-\phi_{s} \frac{\Delta t}{\Delta y}+\phi_{n} \frac{\Delta t}{\Delta y}
\end{aligned}
$$

Selanjutnya pengintegralan persamaan momentum terhadap tiga variabel yaitu $x, y$ dan $t$

$$
\begin{aligned}
& \int_{t}^{t+\Delta t} \int_{y}^{y+\Delta y} \int_{x}^{x+\Delta x}\left[\frac{\partial \rho \phi_{0}}{\partial t}+\frac{\partial \rho u \phi_{w}}{\partial x}-\frac{\partial \rho u \phi_{e}}{\partial x}+\frac{\partial \rho u \phi_{s}}{\partial y}-\frac{\partial \rho u \phi_{n}}{\partial y}\right] d x d y d t= \\
& \int_{t}^{t+\Delta t} \int_{y}^{y+\Delta y} \int_{x}^{x+\Delta x}\left[-\frac{\partial P}{\partial x}-\frac{\partial P}{\partial y}+2 \mu \frac{\partial^{2} u}{\partial x^{2}}+2 \mu \frac{\partial u}{\partial x}+2 \mu \frac{\partial^{2} v}{\partial y^{2}}+2 \mu \frac{\partial v}{\partial y}\right] d x d y d t
\end{aligned}
$$

Diperoleh model akhir dari persamaan momentum sebagai berikut:

$$
\begin{aligned}
& \rho \phi_{0} \Delta y \Delta x+\rho u \phi_{w} \Delta t \Delta y-\rho u \phi_{e} \Delta t \Delta y+\rho v \phi_{s} \Delta t \Delta x-\rho v \phi_{n} \Delta t \Delta x= \\
& -P \Delta t \Delta y-P \Delta t \Delta x+2 \mu u \frac{\Delta t \Delta y}{\Delta x}+2 \mu u \Delta t \Delta x+2 \mu v \frac{\Delta t \Delta x}{\Delta y}+2 \mu v \Delta t \Delta y
\end{aligned}
$$

dengan,

$$
\begin{aligned}
& u=\left(u_{\max }\left(1-\frac{4}{D^{2}} x^{2}-\frac{4}{D^{2}} y^{2}\right)\right) \\
& v=\left(v_{\max }\left(1-\frac{4}{D^{2}} x^{2}-\frac{4}{D^{2}} y^{2}\right)\right) \\
& \mu=\left(k \gamma^{n-1}+\frac{\tau_{0}}{\gamma}\right) \\
& P=\left(-\frac{1}{4}(\cos (k x)+\cos (k y)) \exp \left(\frac{-4 k^{2} t}{\operatorname{Re}}\right)\right)
\end{aligned}
$$

Sehingga persamaan (8) menjadi: 


$$
\begin{aligned}
\rho \phi_{0} \Delta y \Delta x-\left(u_{\max }\left(1-\frac{4}{D^{2}} x^{2}-\frac{4}{D^{2}} y^{2}\right)\right)\left(-\rho \phi_{w} \Delta t \Delta y+\rho \phi_{e} \Delta t \Delta y\right) \\
-\left(v_{\max }\left(1-\frac{4}{D^{2}} x^{2}-\frac{4}{D^{2}} y^{2}\right)\right)\left(-\rho \phi_{s} \Delta t \Delta x+\rho \phi_{n} \Delta t \Delta x\right) \\
=-\left(-\frac{1}{4}(\cos (k x)+\cos (k y)) \exp \left(\frac{-4 k^{2} t}{R e}\right)\right) \Delta t \Delta y \\
-\left(-\frac{1}{4}(\cos (k x)+\cos (k y)) \exp \left(\frac{-4 k^{2} t}{R e}\right)\right) \Delta t \Delta x \\
+2\left(k \gamma^{n-1}+\frac{\tau_{0}}{\gamma}\right)\left(u_{\max }\left(1-\frac{4}{D^{2}} x^{2}-\frac{4}{D^{2}} y^{2}\right)\right) \frac{\Delta t \Delta y}{\Delta x} \\
+2\left(k \gamma^{n-1}+\frac{\tau_{0}}{\gamma}\right)\left(u_{\max }\left(1-\frac{4}{D^{2}} x^{2}-\frac{4}{D^{2}} y^{2}\right)\right) \Delta t \Delta x \\
+2\left(k \gamma^{n-1}+\frac{\tau_{0}}{\gamma}\right)\left(v_{\max }\left(1-\frac{4}{D^{2}} x^{2}-\frac{4}{D^{2}} y^{2}\right)\right) \frac{\Delta t \Delta x}{\Delta y} \\
+2\left(k \gamma^{n-1}+\frac{\tau_{0}}{\gamma}\right)\left(v_{\max }\left(1-\frac{4}{D^{2}} x^{2}-\frac{4}{D^{2}} y^{2}\right)\right) \Delta t \Delta y
\end{aligned}
$$

Penyelesaian model matematika kecepatan aliran darah pada pembuluh darah arteri dan vena akibat kelainan jantung single ventricle dapat diperoleh dari substitusi persamaan (9) ke persamaan (12) sehingga didapat persamaan sebagai berikut:

$$
\begin{aligned}
\phi_{w}\left(\rho u_{\max }(1\right. & \left.\left.-\frac{4}{D^{2}} x^{2}-\frac{4}{D^{2}} y^{2}\right)-\rho\right) \Delta t \Delta y-\phi_{e}\left(\rho u_{\max }\left(1-\frac{4}{D^{2}} x^{2}-\frac{4}{D^{2}} y^{2}\right)-\rho\right) \Delta t \Delta y \\
& +\phi_{s}\left(\rho v_{\max }\left(1-\frac{4}{D^{2}} x^{2}-\frac{4}{D^{2}} y^{2}\right)-\rho\right) \Delta t \Delta x \\
& -\phi_{n}\left(\rho v_{\max }\left(1-\frac{4}{D^{2}} x^{2}-\frac{4}{D^{2}} y^{2}\right)-\rho\right) \Delta t \Delta x \\
& =-\left(-\frac{1}{4}(\cos (k x)+\cos (k y)) \exp \left(\frac{-4 k^{2} t}{R e}\right)\right)(\Delta t \Delta y-\Delta t \Delta x) \\
+ & 2\left(k \gamma^{n-1}+\frac{\tau_{0}}{\gamma}\right)\left(u_{\max }\left(1-\frac{4}{D^{2}} x^{2}-\frac{4}{D^{2}} y^{2}\right)\right)\left(\frac{\Delta t \Delta y}{\Delta x}+\Delta t \Delta x\right) \\
+ & 2\left(k \gamma^{n-1}+\frac{\tau_{0}}{\gamma}\right)\left(v_{\max }\left(1-\frac{4}{D^{2}} x^{2}-\frac{4}{D^{2}} y^{2}\right)\right)\left(\frac{\Delta t \Delta x}{\Delta y}+\Delta t \Delta y\right)
\end{aligned}
$$

\section{KESIMPULAN}

Berdasarkan penelitian yang telah dilakukan diharapkan agar melakukan penelitian dengan menganalisis penyakit atau kelainan jantung yang berbeda selain single ventricle. Model matematika aliran darah pada pembuluh darah arteri dan vena akibat kelainan jantung single ventricle diperoleh dari persamaan massa dan persamaan momentum. Berdasarkan hasil penelitian diperoleh model matematika aliran darah pada pembuluh darah arteri dan vena akibat kelainan jantung Single ventricle dengan fisiologi fontan sebagai berikut: 


$$
\begin{aligned}
\phi_{w}\left(\rho u_{\max }(1\right. & \left.\left.-\frac{4}{D^{2}} x^{2}-\frac{4}{D^{2}} y^{2}\right)-\rho\right) \Delta t \Delta y-\phi_{e}\left(\rho u_{\max }\left(1-\frac{4}{D^{2}} x^{2}-\frac{4}{D^{2}} y^{2}\right)-\rho\right) \Delta t \Delta y \\
& +\phi_{s}\left(\rho v_{\max }\left(1-\frac{4}{D^{2}} x^{2}-\frac{4}{D^{2}} y^{2}\right)-\rho\right) \Delta t \Delta x \\
& -\phi_{n}\left(\rho v_{\max }\left(1-\frac{4}{D^{2}} x^{2}-\frac{4}{D^{2}} y^{2}\right)-\rho\right) \Delta t \Delta x \\
& =-\left(-\frac{1}{4}(\cos (k x)+\cos (k y)) \exp \left(\frac{-4 k^{2} t}{R e}\right)\right)(\Delta t \Delta y-\Delta t \Delta x) \\
& +2\left(k \gamma^{n-1}+\frac{\tau_{0}}{\gamma}\right)\left(u_{\max }\left(1-\frac{4}{D^{2}} x^{2}-\frac{4}{D^{2}} y^{2}\right)\right)\left(\frac{\Delta t \Delta y}{\Delta x}+\Delta t \Delta x\right) \\
+ & 2\left(k \gamma^{n-1}+\frac{\tau_{0}}{\gamma}\right)\left(v_{\max }\left(1-\frac{4}{D^{2}} x^{2}-\frac{4}{D^{2}} y^{2}\right)\right)\left(\frac{\Delta t \Delta x}{\Delta y}+\Delta t \Delta y\right)
\end{aligned}
$$

Model matematika diperoleh berdasarkan faktor-faktor yang mempengaruhi aliran darah pada pembuluh darah arteri dan vena. Model matematika dapat disimulasikan untuk memperoleh hasil numerik yang dapat dibandingkan dengan kondisi sebenarnya, sehingga peneliti lain dapat melakukan simulasi model matematika yang diperoleh.

\section{DAFTAR PUSTAKA}

[1] Putra, A. S. H., Suharto, \& Fatahillah, A. (2017). Analisis Sirkulasi Udara pada Sistem Pernafasan Manusia Menggunakan Metode Volume Hingga. Kadikma, 8(2), 95-104.

[2] Hariyanto, D. (2016). Profil Penyakit Jantung Bawaan di Instalasi Rawat Inap Anak RSUP Dr.M.Djamil Padang Januari 2008 - Februari 2011. Sari Pediatri, 14(3), 152

[3] Cintyandy, R., \& Boom, C. E. (2013). Perioperative Management of Single Ventricle. Indonesian Journal of Cardiology, 33(4), 252-265.

[4] De Leval, M. R., Dubini, G., Migliavacca, F., Jalali, H., Camporini, G., Redington, A., \& Pietrabissa, R. (1996). Use of computational fluid dynamics in the design of surgical procedures: Application to the study of competitive flows in cavopulmonary connections. Journal of Thoracic and Cardiovascular Surgery, 111(3), 502-513.

[5] Ripno, Iswanto. (2011). Pemodelan Matematika Aplikasi dan Terapannya. Yogyakarta: Graha Ilmu.

[6] Cheng, A. L., Pahlevan, N. M., Rinderknecht, D. G., Wood, J. C., \& Gharib, M. (2018). Experimental investigation of the effect of non-Newtonian behavior of blood flow in the Fontan circulation. European Journal of Mechanics, B/Fluids, 68, 184-192.

[7] Fatahillah, A., Dafik, dan Susanto, J. 2015. Analisis Kecepatan Aliran Udara pada Gedung Bertingkat Karena Pengaruh Penghalang di Depannya, Kadikma, vol. 6, no. 2, pp. 75-82.

[8] Fatahillah, A. (2013). Analisis Penyebaran Aliran Panas pada Oven Surya Berbantuan Software Fluent. Kadikma, 2, 1-8.

[9] Hardiyanti, S. A., Dafik, dan Fatahillah, A. (2016). Analisis Kecepatan Aliran Hidrogen Peroksida $\left(\mathrm{H}_{2} \mathrm{O}_{2}\right)$ pada Sterilisasi Saluran Akar Gigi Menggunakan Metode Numerik Volume Hingga, KadikmA, vol. 6, no. 2, pp. 13-26. 
[10] Irawati, L. (2010). Viskositas Darah dan Aspek Medisnya. Majalah Kedokteran Andalas, 34(2), 102-111.

[11] Amirullah, I., Fatahillah, A., \& Setiawan, T. B. (2019). Pemodelan Matematika Aliran Darah pada Arteri Koroner Akibat Pemasangan Stent. Kadikma, 10(1), 6873.

[12] Fatahillah, A. (2013). Pemodelan Dan Penyelesaian Numerik Dari Permasalahan Penyebaran Asap Menggunakan Metode Volume Hingga. Saintifika, Vol. 15((1)), 88-96.

[13] Trisnani, D., Dafik, \& Fatahillah, A. (2014). Analisis Sirkulasi Udara Berdasarkan Kecepatan Awal Udara Pada Tanaman Pelindung Kopi Dan Pola Tanam Graf Tangga Permata Dengan Metode Volume Hingga Pendahuluan Metode Penelitian. Prosiding Seminar Nasional Matematika Dan Pendidikan Matematika, 23-30.

[14] Fatahillah, A. (2014). Analisis Numerik Profil Sedimentasi Pasir pada Pertemuan Dua Sungai Berbantuan Software Fluent. Kadikma, 5(3), 35-40.

[15] Fatahillah, A., Setiawani, S., \& Fatihah, N. N. (2015). Pemodelan dan Simulasi Numerik Sebaran Air Panas Spray Pond Menggunakan Metode Volume Hingga. Saintifika, 17(1), 20-28. 